\title{
Should Canada's approach to COVID-19 and kids change with new variants?
}

\author{
n Cite as: CMAJ 2021 April 26;193:E623-4. doi: 10.1503/cmaj.1095936
}

Posted on cmajnews.com on April 9, 2021.

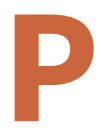

ublic health experts say Canada may need to reconsider its COVID-19 pandemic strategy considering increasing hospitalizations among young people with new variants of SARS-CoV-2.

According to Dr. Brian Conway, medical director of the Vancouver Infectious Diseases Centre, the new variants appear to be causing more severe disease, with most transmissions occurring among people in their 20s and 30s. Meanwhile, there are troubling reports of children playing a bigger role in outbreaks.

"It's driven the pandemic in a different direction than we had planned for, quite clearly," said Conway.

\section{What's the situation in Canada?}

In late March, Canada's chief medical officer warned that the new variants were driving a spike in hospitalizations and more severe outcomes in younger adults, especially those under $40-$ a group that had fared relatively well in the first waves of the pandemic.

Around the same time, Ontario's COVID-19 science advisory table reported that variants of concern accounted for two-thirds of new SARS-CoV-2 infections in the province, and were associated with a $103 \%$ increased risk of admission to intensive care and a 56\% increased risk of death from COVID-19.

More recently, Alberta reported 175 hospitalizations of children and teens since the beginning of the pandemic, up from just 37 in November. Young people aged 5 to 19 have the second-highest COVID-19 rate in the province, behind those aged 20 to 29 .

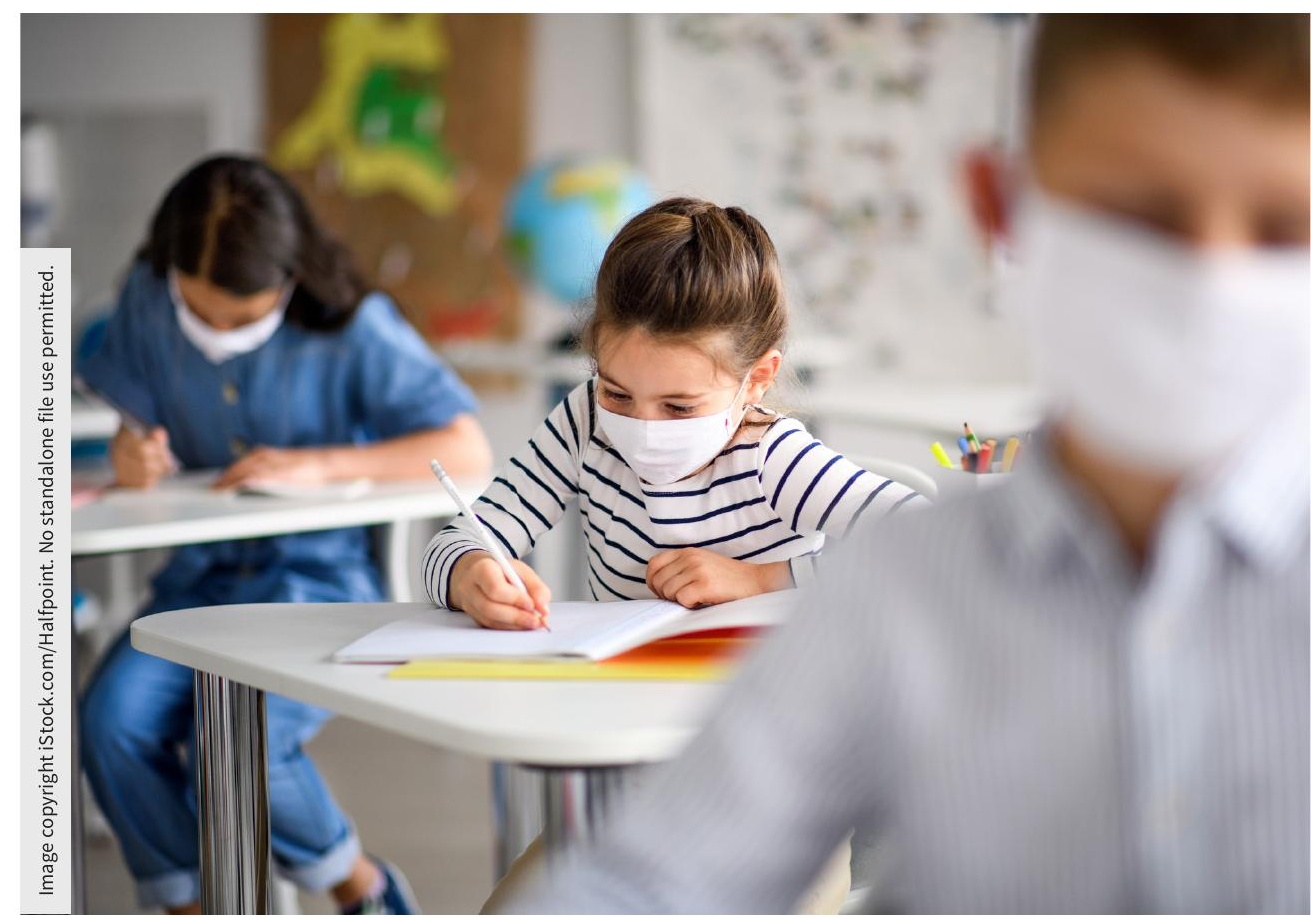

Children and younger adults appear to be playing a bigger role in the spread of new variants of SARS-CoV-2 than previously circulating strains.

\section{What's happening in other countries?}

The most common variant of concern in Canada - B.1.1.7 - has been linked with surges in infections among children in other countries, too.

In the United States, where B.1.1.7 is now the dominant strain of SARS-CoV-2, experts have raised alarm about a spike in infections among children relative to other age groups. Cases are rising across all ages, but for the first time, children aged 10 to 19 account for the largest share.

According to epidemiologist Michael Osterholm, "Our state of Minnesota has a very large and rapidly growing outbreak right now of B.1.1.7 that [was] initially focused in youth sports, transmitted widely in kids in a number of different areas, [and is] now spilling over into parents, grandparents and so forth. It's a totally different virus in the sense of what it's doing epidemiologically."

B.1.1.7 is also a dominant strain in Israel, where more than 50000 children tested positive for the virus in January more than any month before. In Italy, 10\% of the village of Corzano tested positive in February, and $60 \%$ of those infections were among young children and infants, many of whom may have infected other family members. 


\section{Should Canada pivot its pandemic} response?

Recent research in CMAJ suggested children were unlikely to be the main drivers of the pandemic before new variants emerged, and it's not yet clear how much their risk relative to other age groups may have changed.

High-quality epidemiological studies take time, said Dr. Guillaume Poliquin, acting scientific director general of Canada's National Microbiology Laboratory. Meanwhile, there may be complex factors contributing to increased transmission among young people.

"For example, part of the driver in the younger age groups in the U.K was... transmission within households," said Poliquin. Given that B.1.1.7 and other variants are much more transmissible in general, a person's age may not matter as much as being "in a household with a family member that has a variant."

A recent study in Science found that an overall increase in transmissibility best explained the rapid spread of new variants in England. The authors noted that increased susceptibility among children could also explain changing infection patterns but wasn't well supported by how the virus spread within families.
Even so, "the more efficient spread of the variant implies that the difficult societal decision of closing schools will be a key public health question for multiple countries in the months ahead."

Likewise, a research letter in BMJ suggested that the reproduction rate of B.1.1.7 and similar variants appear to be slightly but not certainly below 1 for kids and around 1 for teens - which could "qualitatively change the nature of SARSCoV-2 spread in school settings from sinks of infection to amplifiers of infection." As such, "more stringent mitigation measures may become necessary as schools reopen."

Poliquin and Conway agreed that Canada needs to step up genetic testing and surveillance for the variants to better understand where transmission is happening and target interventions.

Conway also said it may be time to reconsider Canada's aged-based vaccine strategy which has prioritized older adults. With increasing spread among younger people, "it may be that we need to retarget vaccines towards that population to try and interrupt transmission chains," he said. "We need to rethink our vaccine strategy a fair bit to address this."

According to Dr. Peter Jüni of Ontario's COVID-19 science advisory table, it's important to consider whether an agebased approach still makes sense versus vaccinating as many people as possible, especially those in higher-risk settings and households. "Not only should we get the essential workers, but also the families of essential workers who are at tremendously high risk to develop the disease."

Speaking prior to spring closures in Ontario, Jüni said schools could still be relatively safe with classroom bubbles, masking, and better ventilation. "If we let it slip outside of school, and classes start to mix with birthday parties or [in] schoolyards where kids are not masked properly, then it gets really problematic," he said. "We should assume now [although] we don't know for sure - that children are as likely to play a role in this pandemic as adults, irrespective of age."

\section{Diana Duong, CMAJ}

Content licence: This is an Open Access article distributed in accordance with the terms of the Creative Commons Attribution (CC BY-NC-ND 4.0) licence, which permits use, distribution and reproduction in any medium, provided that the original publication is properly cited, the use is noncommercial (i.e., research or educational use), and no modifications or adaptations are made. See: https://creativecommons.org/ licenses/by-nc-nd/4.0/ 